\title{
Underground hydrogen storage: application of geochemical modelling in a case study in the Molasse Basin, Upper Austria
}

\author{
Neda Hassannayebi ${ }^{1} \cdot$ Siroos Azizmohammadi ${ }^{1} \cdot$ Marco De Lucia $^{2} \cdot$ Holger Ott $^{1}$
}

Received: 25 January 2018 / Accepted: 20 December 2018 / Published online: 28 February 2019

(c) The Author(s) 2019

\begin{abstract}
Hydrogen storage in depleted gas fields is a promising option for the large-scale storage of excess renewable energy. In the framework of the hydrogen storage assessment for the "Underground Sun Storage" project, we conduct a multi-step geochemical modelling approach to study fluid-rock interactions by means of equilibrium and kinetic batch simulations. With the equilibrium approach, we estimate the long-term consequences of hydrogen storage, whereas kinetic models are used to investigate the interactions between hydrogen and the formation on the time scales of typical storage cycles. The kinetic approach suggests that reactions of hydrogen with minerals become only relevant over timescales much longer than the considered storage cycles. The final kinetic model considers both mineral reactions and hydrogen dissolution to be kinetically controlled. Interactions among hydrogen and aqueous-phase components seem to be dominant within the storage-relevant time span. Additionally, sensitivity analyses of hydrogen dissolution kinetics, which we consider to be the controlling parameter of the overall reaction system, were performed. Reliable data on the kinetic rates of mineral dissolution and precipitation reactions, specifically in the presence of hydrogen, are scarce and often not representative of the studied conditions. These uncertainties in the kinetic rates for minerals such as pyrite and pyrrhotite were investigated and are discussed in the present work. The proposed geochemical workflow provides valuable insight into controlling mechanisms and risk evaluation of hydrogen storage projects and may serve as a guideline for future investigations.
\end{abstract}

Keywords Underground hydrogen storage $\cdot$ Depleted gas reservoir $\cdot$ Geochemical modelling $\cdot$ Rock-fluid interactions

\section{Introduction}

Hydrogen is an effective energy carrier that can be generated from excess renewable energy, which is a technique called peak shaving. Hydrogen is considered as an alternative to fossil fuels in the transport sector. However, peak shaving requires large-scale storage options, orders of magnitude larger than typically discussed in relation to mobility and transportation and other applications. Taylor et al. (1986)

This article is part of a Topical Collection in Environmental Earth Sciences on "Subsurface Energy Storage II", guest edited by Zhonghe Pang, Yanlong Kong, Haibing Shao, and Olaf Kolditz.

Neda Hassannayebi

neda.hassannayebi@unileoben.ac.at

1 Department Petroleum Engineering, Montanuniversität Leoben, 8700 Leoben, Austria

2 GFZ German Research Centre for Geosciences, Section 3.4 Fluid Systems Modeling, Telegrafenberg, 14473 Potsdam, Germany evaluated the technical and economic aspects of hydrogen storage in large quantities using five site-specific scenarios: (1) pressure vessel storage, (2) liquid hydrogen for aircrafts, (3) salt cavern storage, (4) mined cavern storage and (5) underground porous media storage. According to their study, underground hydrogen storage (UHS) is the most economical means of storing large quantities of gaseous hydrogen. Foh et al. (1979) presented a few examples of UHS projects, including the successful hydrogen storage in solution-mined salt caverns at Teeside in England by Imperial Chemical Industries and hydrogen storage in an aquifer reservoir site near Beynes, France, which was operated by Gaz de France to store hydrogen-rich gas (50-60\%) from 1950 to 1972. Apart from these case studies and a few more projects, there has never been a pilot test on using depleted gas reservoirs as hydrogen storage sites.

Depleted natural gas reservoirs provide massive storage capacity and are therefore suitable for large-scale UHS facilities. Gas reservoirs have proven to be sealed; however, because of the lack of field pilots, there is not much 
knowledge about hydrogen-induced fluid-rock interactions for such reservoirs, and an assessment of economic and environmental risks is needed for commercial implementation of UHS projects. Possible risks associated with UHS include operational losses, corrosion, leakage through the casing, diffusion of gas into the caprock, the solubility of hydrogen into the brine formation, and chemical and biochemical reactions (Carden and Paterson 1979).

A small depleted gas field located in the Molasse Basin in Upper Austria has been selected as a suitable storage site and as a target for the integrated pilot project "Underground Sun Storage", which for the first time tests the storage of hydrogen generated from a surplus of renewable resources in a depleted gas reservoir ((UNDERGROUND. SUN.STORAGE 2016, http://www.underground-sun-stora ge.at/). The Molasse Basin, situated between Linz and Salzburg, is one of the main gas-producing regions in Austria. To date, more than 40 gas fields have been discovered in this basin. Many of these gas fields are found in deepwater sandstone, conglomerates of the Oligocene-Miocene Puchkirchen and Hall formations (De Ruig and Hubbard 2006). This field exhibits unique characteristics as it is homogenous, optimally sealed by shale layers and without connections to aquifers, which makes it a promising site for a pilot project. The reservoir layer is characterized by a thickness of $1.5 \mathrm{~m}, 22 \%$ porosity, $22 \%$ irreducible water saturation and a temperature of $40^{\circ} \mathrm{C}$.

In this work, we developed a workflow to evaluate gas-brine-mineral interactions. The proposed workflow starts with investigating the geochemical system through equilibrium batch modelling, where reactions are considered to be instantaneous. Even though outcomes of the equilibrium model are not apt for a typical hydrogen storage cycle, they are still valuable as indicator of long-term risk assessment for hydrogen storage projects. As the second step, we include the kinetics for mineral reactions, while hydrogen solubility and thus availability for reactants are assumed to be at equilibrium with the gas phase. This step quantifies the alteration of the mineral phase during a typical hydrogen storage cycle, which is assumed to be on the order of 3-6 months. Lastly, to have a more realistic geochemical model, we consider both the mineral and hydrogen availability in reactions to be kinetically controlled. Owing to the lack of knowledge/scarcity of data concerning reaction rates among hydrogen and reservoir brines, we instead investigated the sensitivity of the results to the reaction rate parameters as a result of hydrogen injection.

\section{Field data}

The availability of data from small gas fields is typically limited. Water and gas samples were available for this formation; however, no core sample was extracted. Data on a core sample from a well of a nearby reservoir were used as analogue for the mineralogy, as we assume similar mineralogy to the field studied here. The equilibrium between the initial brine and mineral phases is assumed and is considered in this study by an initial equilibration step in the numerical simulations.

\section{Production-injection scheme}

Gas production of this field started in June 2007, and the well was ceased at the end of June 2010. The well was shut in until October 2015. Thereafter, a hydrogen-methane mixture was injected in three subsequent periods. Two of these periods lasted for only a few days because of a shortage of hydrogen at the site. In the third attempt, hydrogen was injected into the formation for 3 months. Figure 1 illustrates the sequence of events for this reservoir.

\section{Rock and fluid compositions}

X-ray diffraction (XRD) data were used to characterize the volumetric mineral compositions of the formation rock. The analyzed core sample was taken from a nearby well and is assumed to have a similar composition as the reservoir under investigation. The mineral composition is as follows: quartz (20 vol\%), muscovite and clay minerals (47 vol\%), subordinate plagioclase (4 vol\%), K-feldspar (2 vol\%), calcite (20 vol\%), dolomite (9 vol\%), ankerite (4 vol\%), siderite (2 vol\%), and pyrite (1 vol\%). In this study, clay minerals were assumed to make up approximately $40 \mathrm{vol} \%$ of the total reservoir volume. The volumetric percentage of clay particles is given as follows: illite (59 vol\%), smectite (29 vol\%), chlorite (15 vol\%) and kaolinite (3 vol\%) (analysis performed by OMV Exploration \& Production GmbH Laboratory, 2007).

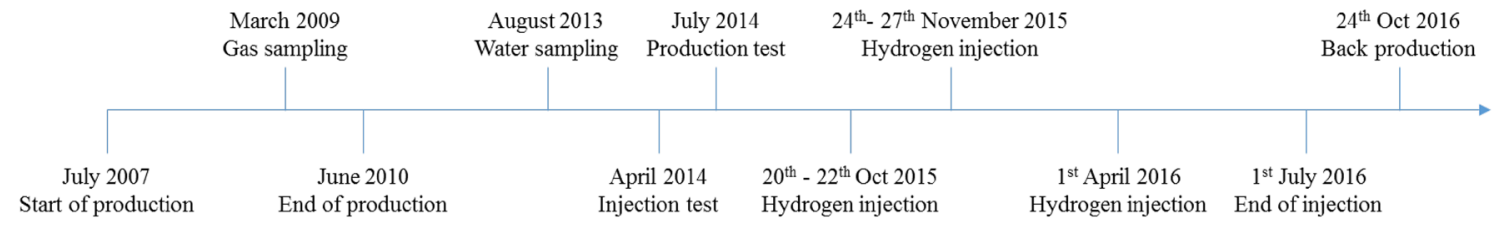

Fig. 1 Sequence of events in Lehen-2 
The volumetric percentage of minerals was converted to mole values for each mineral to be used in the geochemical models. Using Eq. (1), the amount of each mineral was calculated as:

$n_{\text {mineral }}=\frac{m_{\mathrm{w}}}{\rho_{\mathrm{w}}}\left(\frac{1-\phi}{\phi}\right) \frac{\rho_{\text {mineral }}}{M_{\text {mineral }}} \cdot \mathrm{SVF}$,

where $\rho_{\mathrm{w}}$ is water density, $m_{\mathrm{w}}$ is water mass (basis $=1 \mathrm{~kg}$ ), $\phi$ is porosity, $\rho_{\text {mineral }}$ is the mineral density, SVF is the solid volume fraction of minerals, $M_{\text {mineral }}$ is mineral molar weight, and $n_{\text {mineral }}$ is the number of moles of each mineral.

The formation water was sampled from the well under investigation and is mainly dominated by $\mathrm{K}^{+}, \mathrm{Cl}^{-}, \mathrm{HCO}_{3}{ }^{-}$, and $\mathrm{Na}^{+}$, with considerable amounts of $\mathrm{SO}_{4}{ }^{2-}, \mathrm{Mg}^{2+}$, $\mathrm{NO}_{3}{ }^{-}, \mathrm{NH}_{4}{ }^{+}, \mathrm{Ca}^{2+}$ and some dissolved $\mathrm{Fe}^{2+}$ and $\mathrm{Mn}^{2+}$ (see Table 1).

The initial gas composition of the studied reservoir [sampled by RAG (Rohöl-Aufsuchungs Aktiengesellschaft)] consists of $\mathrm{CH}_{4}(98.33 \mathrm{~mol} \%), \mathrm{C}_{2} \mathrm{H}_{6}(0.49 \mathrm{~mol} \%), \mathrm{CO}_{2}$ $(0.08 \mathrm{~mol} \%)$ and $\mathrm{N}_{2}(0.84 \mathrm{~mol} \%)$. The maximum sulfide content $\left(\mathrm{H}_{2} \mathrm{~S}\right)$ is reported to be $5 \mathrm{mg} / \mathrm{m}^{3}$. The initial reservoir pressure is around 100 bars. The amount of $\mathrm{CO}_{2}$ in the gas phase is incorporated in the geochemical models to account for the degassing effect during water sampling.

\section{Geochemical modelling approach}

\section{Modelling tool and thermodynamic database}

Geochemist's workbench (GWB) (Bethke et al. 2018) was used as a geochemical modelling tool for this study. The software has numerous capabilities, such as the implementation

Table 1 Chemical composition of the brine sample from the well under investigation (analysis performed by Dr Begert Umweltconsulting $\mathrm{GmbH}, 2013$ )

\begin{tabular}{lll}
\hline Aqueous species & Measured value $(\mathrm{mg} / \mathrm{L})$ & $\begin{array}{l}\text { Measured } \\
\text { value } \\
(\text { molal })\end{array}$ \\
\hline $\mathrm{NH}_{4}{ }^{+}$ & 13.5 & $7.53 \mathrm{E}-04$ \\
$\mathrm{NO}_{2}{ }^{-}$ & $<0.010$ & $2.19 \mathrm{E}-07$ \\
$\mathrm{Cl}^{-}$ & 5900 & $1.95 \mathrm{E}-01$ \\
$\mathrm{NO}_{3}{ }^{-}$ & 12.4 & $2.01 \mathrm{E}-04$ \\
$\mathrm{Mg}^{2+}$ & 12.3 & $5.09 \mathrm{E}-04$ \\
$\mathrm{SO}_{4}{ }^{2-}$ & 16.9 & $1.77 \mathrm{E}-04$ \\
$\mathrm{Ca}^{2+}$ & 7.23 & $1.81 \mathrm{E}-04$ \\
$\mathrm{Fe}^{2+}$ & 0.31 & $5.58 \mathrm{E}-06$ \\
$\mathrm{Mn}^{2+}$ & 0.088 & $1.61 \mathrm{E}-06$ \\
$\mathrm{Na}^{+}$ & 181 & $7.92 \mathrm{E}-03$ \\
$\mathrm{~K}^{+}$ & 7820 & $2.01 \mathrm{E}-01$ \\
$\mathrm{HCO}_{3}^{-}$ & 943 & $1.55 \mathrm{E}-02$ \\
\hline
\end{tabular}

of kinetic rate laws for mineral dissolution and precipitation reactions, complex association and dissociation, redox transformation, gas transfer, 1-D and 2-D reactive transport, and bio-reactive and colloidal transport (Aqueous Solutions 2016, http://www.gwb.com/).

The internal LLNL thermodynamic database (Lawrence Livermore National Laboratory) was used throughout the study. Consistent and comprehensive thermodynamic data are key to the accurate evaluation of the quality and accuracy of the geochemical model. Database consistency and completeness with respect to the mineralogy of the reservoir were checked. Aside from subordinate plagioclase, potassium feldspar, ankerite, illite, smectite and chlorite, data for the rest of primary minerals are present in this database. Our strategy for modelling was to look up the thermodynamic properties of the absent minerals and integrate them into the LLNL database. Proxy minerals were chosen for minerals for which thermodynamic properties could not be found. The thermodynamic properties of ankerite (Holland and Powell 1998) were integrated directly into the database. Montmorillonite was chosen to represent the smectite group. Albite and anorthite were chosen as proxy minerals for plagioclase. Microcline was selected as an alternative mineral for potassium feldspar. Finally, clinochlore and daphnite were chosen as the two end members of chlorite. Table 2 illustrates the final set of minerals used in the geochemical study.

\section{Modelling methodology}

As part of the UHS feasibility assessment, a multistep methodology is proposed (Fig. 2) to characterize the behaviour of the geochemical system in the presence of hydrogen. As at the time of the study, there were no data available to be benchmarked with the simulation results, several scenarios applying different assumptions were simulated. In the course of modelling relative adjustments and assumptions are incorporated into the models to have results that are more representative of what might happen in the field during a storage cycle. Even though we believe the final kinetic batch model has the highest relevance for the specific study, other scenarios as well as the long-term storage consequences under elevated conditions (longer time scales or elevated temperatures) should not be overlooked.

In this approach, we suggest different modelling steps to study the short- and long-term impacts of hydrogen on the reservoir; proper assumptions were considered for all stages of modelling. The modelling steps are: (1) the equilibrium batch model, which assumes instantaneous reactions (equilibrium) for both hydrogen and minerals; (2) the primary kinetic batch model, which considers mineral reactions to be kinetically controlled, while hydrogen reactions are assumed to occur at local thermodynamic equilibrium; this stage is composed of two modelling steps. In the first model, all the 
Table 2 The final minerals' assemblage used in the geochemical models

\begin{tabular}{|c|c|c|c|c|c|}
\hline & Primary minerals & $\begin{array}{l}\text { Alternative/substi- } \\
\text { tuted minerals }\end{array}$ & $\begin{array}{l}\text { Final mineral assem- } \\
\text { blage used in models }\end{array}$ & $\begin{array}{l}\text { Calculated min- } \\
\text { erals (moles) }\end{array}$ & Chemical formula \\
\hline \multirow[t]{10}{*}{ Rock minerals } & Quartz & & Quartz & 25.91 & $\mathrm{SiO}_{2}$ \\
\hline & Muscovite & & Muscovite & 1.47 & $\mathrm{KAl}_{2}\left(\mathrm{AlSi}_{3} \mathrm{O}_{10}\right)(\mathrm{OH})_{2}$ \\
\hline & Calcite & & Calcite & 9.57 & $\mathrm{CaCO}_{3}$ \\
\hline & Dolomite & & Dolomite & 4.12 & $\mathrm{CaMg}\left(\mathrm{CO}_{3}\right)_{2}$ \\
\hline & Ankerite & & Ankerite & 1.76 & $\mathrm{Ca}\left(\mathrm{Fe}^{2+} \mathrm{Mg}, \mathrm{Mn}\right)\left(\mathrm{CO}_{3}\right)_{2}$ \\
\hline & \multirow[t]{2}{*}{ Subordinate plagioclase } & Albite & Albite & 0.59 & $\mathrm{NaAlSi}_{3} \mathrm{O}_{8}$ \\
\hline & & Anorthite & Anorthite & 0.57 & $\mathrm{Ca}\left[\mathrm{Al}_{2} \mathrm{Si}_{2} \mathrm{O}_{8}\right]$ \\
\hline & Potassium feldspar & Microcline & Microcline & 0.55 & $\mathrm{KAlSi}_{3} \mathrm{O}_{8}$ \\
\hline & Siderite & & Siderite & 2.03 & $\mathrm{Fe}^{2+}\left(\mathrm{CO}_{3}\right)$ \\
\hline & Pyrite & & Pyrite & 1.24 & $\mathrm{FeS}_{2}$ \\
\hline \multirow[t]{5}{*}{ Clay fraction } & Illite & & Illite (FeII) & 1.63 & $\mathrm{~K}_{0.85} \mathrm{Fe}_{0.25} \mathrm{Al}_{2.35} \mathrm{Si}_{3.4} \mathrm{O}_{10}(\mathrm{OH})_{2}$ \\
\hline & Smectite & K-montmorillonite & K-montmorillonite & 0.45 & $\begin{array}{c}\mathrm{KSi}_{10.473} \mathrm{Al}_{4.132} \mathrm{Mg}_{0.737} \mathrm{Fe}^{\mathrm{III}} \\
{ }_{0.237} \mathrm{Fe}_{0.211}^{\mathrm{II}} \mathrm{O}_{44.316} \mathrm{H}_{30.737}\end{array}$ \\
\hline & \multirow[t]{2}{*}{ Chlorite } & Clinochlore & Clinochlore & 1.04 & $\mathrm{Mg}_{6} \mathrm{Si}_{4} \mathrm{O}_{10}(\mathrm{OH})_{8}$ \\
\hline & & Daphnite & Daphnite & 1.07 & $\mathrm{Fe}_{5} \mathrm{Al}_{2} \mathrm{Si}_{3} \mathrm{O}_{10}(\mathrm{OH})_{8}$ \\
\hline & Kaolinite & & Kaolinite & 2.39 & $\mathrm{Al}_{2} \mathrm{Si}_{2} \mathrm{O}_{5}(\mathrm{OH})_{4}$ \\
\hline
\end{tabular}

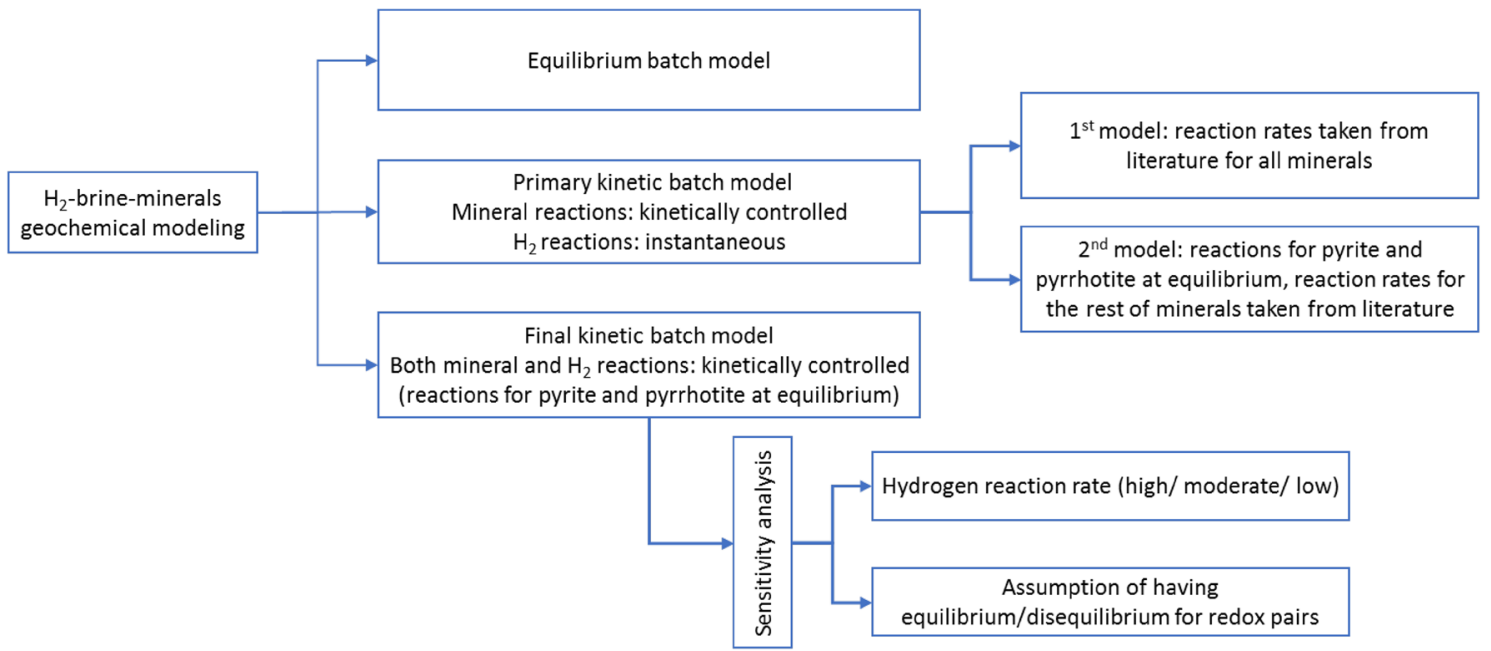

Fig. 2 The geochemical modelling workflow as proposed and applied in this work

mineral reactions are taken from literature data, and in the second, reactions of pyrite and pyrrhotite are assumed to take place at equilibrium. The reason for doing this relates to experimental evidence indicating that these reactions are relatively fast in the presence of hydrogen, while the literature data do not consider this fact. Further discussions are given in the results section. The last step (3) is the final kinetic batch model, in which both minerals and hydrogen reactions are assumed to be kinetically controlled. A sensitivity analysis on the hydrogen reaction rate (low/moderate/high) and the assumption of having equilibrium/disequilibrium for redox pairs is made to investigate their significance on the results.

The results obtained from the equilibrium batch model assist in estimating the long-term consequences of hydrogen injection in the reservoir. However the model has its limitations to predict sensible results for the cyclic hydrogen storage, therefore, it should only be looked at as part of risk assessment study. From the primary kinetic batch model, we conclude that $\mathrm{H}_{2}$ interactions with minerals require time scales much larger than a typical hydrogen storage cycle. Consequently, the interactions among hydrogen and brine components are recognised to be more 
relevant within the storage cycle of hydrogen. Because of the general lack of knowledge concerning the rates of hydrogen dissolution in brine, a sensitivity analysis on $\mathrm{H}_{2}$ reaction-controlling parameters was performed in the final kinetic batch model. With the kinetic approach, a case was studied in which reactions of pyrite and pyrrhotite are considered at equilibrium. This imitates the reduction of pyrite to pyrrhotite, which can be significant at lowtemperature conditions in the presence of hydrogen.

\section{Charge balance analysis}

One of the main steps in geochemical modelling is the charge balance calculation to determine the accuracy of the brine analysis. A routine criterion to evaluate this is the charge balance error (CBE) of the reported cation and anion concentrations, as follows (Freeze and Cherry 1979):

$\mathrm{CBE}=\frac{\sum \text { cations }-\mid \sum \text { anions } \mid}{\mid \sum \text { cations }|+| \sum \text { anions } \mid}$

The concentration unit in Eq. (2) is milliequivalents per litre. The conversion factor from milligram per litre to milliequivalents per litre is taken from (Zhu and Anderson 2002) and has been used for the charge balance calculation. According to Freeze and Cherry (1979), a charge balance error of less than 5\% is acceptable for most laboratories. The result of the analysis is shown in Table 3. The calculated CBE is $17 \%$ for the water sample, which indicates that the initial water composition needs to be reassessed. In the course of modelling, the charge balance was compensated by varying the $\mathrm{Cl}^{-}$concentration.

Table 3 Calculated milliequivalents per liter value for the aqueous species

\begin{tabular}{llll}
\hline Component & Measured $(\mathrm{mg} / \mathrm{L})$ & Charge & $(\mathrm{meq} / \mathrm{L})$ \\
\hline $\mathrm{NH}_{4}{ }^{+}$ & 13.5 & 1 & 0.74844 \\
$\mathrm{NO}_{2}{ }^{-}$ & $<0.010(+)$ & -1 & -0.00022 \\
$\mathrm{Cl}^{-}$ & 5900 & -1 & -166.439 \\
$\mathrm{NO}_{3}{ }^{-}$ & 12.4 & -1 & -0.20001 \\
$\mathrm{Mg}^{2+}$ & 12.3 & 2 & 1.012167 \\
$\mathrm{SO}_{4}{ }^{2-}$ & 16.9 & -2 & -0.35186 \\
$\mathrm{Ca}^{+}$ & 7.23 & 2 & 0.360777 \\
$\mathrm{Fe}^{2+}$ & 0.31 & 2 & 0.013877 \\
$\mathrm{Mn}^{2+}$ & 0.088 & 2 & 0.0364 \\
$\mathrm{Na}^{+}$ & 181 & 1 & 7.8735 \\
$\mathrm{~K}^{+}$ & 7820 & 1 & 247.0338 \\
$\mathrm{HCO}_{3}{ }^{-}$ & 943 & -1 & -15.4558 \\
$\mathrm{Charge} \mathrm{balance} \mathrm{error}^{+}$ & & $17 \%$ & \\
\hline
\end{tabular}

\section{Initial equilibrium state}

As the charge imbalance error was higher than acceptable, the measured initial water composition needs to be reevaluated and corrected. Generally, prior to geochemical simulations, a proper chemical equilibrium state between brine and primary mineral assemblage states must be established to have a consistent and reliable initial system (Klein et al. 2013; Cantucci et al. 2009; De Lucia et al. 2012). Incorporating all detected minerals in the equilibration step leads to numerical issues and does not represent the water sample taken from the well. Thus, we calculated various scenarios to establish the initial state of the system. These scenarios enable us to consider different starting states for our models to account for incompatibilities in the mineralogy and brine sample (note that the rock sample is from a nearby reservoir). The purpose of establishing an "initial equilibrium state" is to identify mineral phases that control the concentrations of aqueous species, to make hypotheses about the equilibrium between brine and rock mineralogy and to estimate the concentrations of missing species (such as $\mathrm{Al}^{3+}$ and $\mathrm{Si})$. Various representations of the mineral composition were equilibrated with the aqueous phase to determine the initial brine compositions. For each case, the calculated brine concentrations were compared to the measured values. Based on the reported natural gas phase in the reservoir, $\mathrm{CO}_{2}$ with the fugacity of 0.08 , was included in the models. With this step, the loss of dissolved $\mathrm{CO}_{2}$ during the water sampling was taken into account. We further excluded $\mathrm{NH}_{4}{ }^{+}, \mathrm{NO}_{2}{ }^{-}$and $\mathrm{NO}_{3}{ }^{-}$from the calculations as there is no indication of minerals containing nitrogen. Another reason for eliminating these species is due to not expecting the nitrate reduction by $\mathrm{H}_{2}$ in the absence of bacteria, or any other specific catalysts (Fanning 2000; Truche et al. 2013a, b). It is worth noticing the co-existence of these redox species will require further discussions and investigations as it has strong association in term of oxygen fugacity in the system, likewise on the redox disequilibrium. Investigation of the latter is beyond the scope of this work. Small initial amounts of $\mathrm{Al}^{3+}$ and $\mathrm{SiO}_{2}$ (aq) were added into the calculations to represent minerals containing these components (e.g., clay minerals). Table 4 presents four scenarios representing different mineral compositions from high to low complexity.

Imposing equilibrium conditions in all scenarios results in inconsistencies with regard to the $\mathrm{Cl}^{-}$and $\mathrm{HCO}_{3}{ }^{-}$concentrations. In the first scenario, the assumed equilibrium state of both dolomite and calcite resulted in an overestimation of $\mathrm{Ca}^{2+}$ and $\mathrm{HCO}_{3}{ }^{-}$ion concentrations. Similarly, $\mathrm{SiO}_{2}$ (aq) was overestimated because of the assumption of equilibrium for muscovite and microcline. In the second scenario, calcite was excluded from the equilibrium model, which led to a better match for $\mathrm{Ca}^{2+}$ and $\mathrm{HCO}_{3}{ }^{-}$. In the third case study, microcline was eliminated from the equilibrium model, 
Table 4 Simulated and measured brine compositions

\begin{tabular}{llllll}
\hline $\begin{array}{l}\text { Aqueous concen- } \\
\text { tration/minerals } \\
\text { included }\end{array}$ & Case study 1 & Case study 2 & Case study 3 & Case study 4 & Measured value (mg/L) \\
\hline $\mathrm{Al}^{3+}$ & & & & & \\
$\mathrm{Ca}^{2+}$ & $9.0 \mathrm{E}-01$ & $9.0 \mathrm{E}-01$ & $1.2 \mathrm{E}-01$ & $0.6 \mathrm{E}-01$ & Not determined \\
$\mathrm{Cl}^{-}$ & 67.22 & 7.46 & 7.46 & 7.34 & 7.23 \\
$\mathrm{Fe}^{2+}$ & 6820.37 & 6820.53 & 6820.54 & 6820.54 & 5900 \\
$\mathrm{HCO}_{3}{ }^{-}$ & 0.48 & 0.48 & 0.48 & 0.31 & 0.31 \\
$\mathrm{~K}^{+}$ & 1109 & 1022 & 1021 & 1021 & 943 \\
$\mathrm{Mg}^{2+}$ & 7820.55 & 7820.73 & 7819.62 & 7819.59 & 7820 \\
$\mathrm{Mn}^{2+}$ & 12.40 & 12.40 & 12.40 & 11.03 & 12.3 \\
$\mathrm{Na}^{+}$ & 0.09 & 0.09 & 0.09 & 0.087 & 0.088 \\
$\mathrm{SO}_{4}{ }^{2-}$ & 180.99 & 180.99 & 180.99 & 180.98 & 181 \\
$\mathrm{SiO}{ }_{2}(\mathrm{aq})$ & 17.14 & 17.14 & 17.14 & 16.89 & 16.9 \\
Dolomite & 5.46 & 5.46 & $2.6 \mathrm{E}-01$ & $1.3 \mathrm{E}-01$ & Not determined \\
$\mathrm{Muscovite}^{2+}$ & $\mathrm{X}$ & $\mathrm{X}$ & $\mathrm{X}$ & $\mathrm{X}$ & \\
$\mathrm{Pyrite}^{\text {Ankerite }}$ & $\mathrm{X}$ & $\mathrm{X}$ & $\mathrm{X}$ & $\mathrm{X}$ & \\
Microcline & $\mathrm{X}$ & $\mathrm{X}$ & $\mathrm{X}$ & $\mathrm{X}$ & \\
$\mathrm{Calcite}$ & $\mathrm{X}$ & $\mathrm{X}$ & $\mathrm{X}$ & & \\
$\mathrm{pH}^{\mathrm{Pe}}$ & $\mathrm{X}$ & $\mathrm{X}$ & & & \\
\hline & 7.59 & 7.6 & 7.6 & 7.6 & 8.7 \\
\hline & -4.22 & -4.13 & -4.13 & -3.95 & Not determined \\
\hline
\end{tabular}

The different case studies and scenarios result in equilibrium assumptions for different sets of minerals in aqueous solution. Case studies 3 and 4 will be used in the following as initial brine compositions which improved the $\mathrm{SiO}_{2}(\mathrm{aq})$ concentration. Scenario 4, which assumes equilibrium among the fewest minerals and the analytical brine (incorporated minerals represent entirely analytical brine components), gives the best match, and the $\mathrm{Fe}^{2+}$ and $\mathrm{Ca}^{2+}$ concentrations improved. Further studies considering hydrogen injection in the equilibrium batch models performed based on the initial states derived from scenarios 3 and 4.

\section{Kinetics of precipitation and dissolution}

The dissolution rate constants at standard conditions, activation energies and specific surface areas for minerals of interest were taken from literature (Table 5); most of the data were obtained from Palandri and Kharaka (2004). Mineral reactions often depend on $\mathrm{pH}$, requiring different kinetic rates for acidic, neutral and basic reaction mechanisms. Normally, all three mechanisms are not incorporated in geochemical modelling applications, e.g., in applications of $\mathrm{CO}_{2}$ storage; often, only neutral or acidic mechanisms are employed (Gaus et al. 2008). In the present case, the reservoir conditions are of high $\mathrm{pH}$, as indicated by the initial brine composition and by the results of the equilibrium approach, which shows an increasing tendency of $\mathrm{pH}$ with the injection of $\mathrm{H}_{2}$. For this reason, only the basic reaction mechanisms for minerals have been used in this study. For minerals for which no basic reaction data are published, data for neutral mechanisms have been used. Due to the scarcity of experimental precipitation rates in the literature, the precipitation rates for secondary minerals were set equal to dissolution rates. It is noteworthy to mention that the precipitation rates for some minerals can be slower than the respective dissolution rates. GWB implements the Lasaga type of reaction rate law:

$r_{k}^{\rightarrow}=A_{\mathrm{s}} k_{+}\left(1-\frac{Q}{K}\right)$

where $r_{k}$ is the reaction rate $(\mathrm{mol} / \mathrm{s}), A_{\mathrm{s}}$ is the mineral's surface area $\left(\mathrm{cm}^{2}\right), k_{+}$is the rate constant $\left(\mathrm{mol} /\left(\mathrm{cm}^{2} \mathrm{~s}\right)\right)$, and $Q$ and $K$ represent the activity product and equilibrium constant for the dissolution reaction, respectively. The surface area is calculated from the specific surface area $\left(\mathrm{cm}^{2} / \mathrm{g}\right)$. The temperature dependence of the reaction rate constant is described by the law of Arrhenius:

$k_{+}=A \mathrm{e}^{-E_{\mathrm{A}} / R T_{K}}$.

Here, $A$ is the pre-exponential Arrhenius factor, $E_{\mathrm{A}}$ is the activation energy, $R$ is the gas constant and $T_{\mathrm{K}}$ is the absolute temperature in Kelvin. Since we have no information on the effective reactive surface area, we use typical values of $10 \mathrm{~cm}^{2} / \mathrm{g}$ for non-clay minerals and $100 \mathrm{~cm}^{2} / \mathrm{g}$ for clay minerals.

Generally, kinetic parameters are obtained in the absence of hydrogen, which makes their precision and 
Table 5 pH-dependent kinetic reaction rate constants at $25^{\circ} \mathrm{C}$ [mainly from Palandri and Kharaka (2004)]

\begin{tabular}{|c|c|c|c|c|c|c|c|c|c|}
\hline \multirow[t]{3}{*}{ Mineral } & \multirow[t]{3}{*}{$A^{\mathrm{a}}\left(\mathrm{cm}^{2} / \mathrm{g}\right)$} & \multicolumn{8}{|c|}{ Kinetic rate parameters } \\
\hline & & \multicolumn{3}{|l|}{ Acid mechanism } & \multicolumn{2}{|c|}{ Neutral mechanism } & \multicolumn{3}{|l|}{ Base mechanism } \\
\hline & & $\mathrm{K}_{25}^{\mathrm{b}}\left(\mathrm{mol} / \mathrm{m}^{2} \mathrm{~s}\right)$ & $\mathrm{Ea}^{\mathrm{c}}(\mathrm{KJ} / \mathrm{mol})$ & $\mathrm{n}^{\mathrm{d}}\left(\mathrm{H}^{+}\right)$ & $\mathrm{K}_{25}\left(\mathrm{~mol} / \mathrm{m}^{2} \mathrm{~s}\right)$ & $\mathrm{Ea}(\mathrm{KJ} / \mathrm{mol})$ & $\mathrm{K}_{25}\left(\mathrm{~mol} / \mathrm{m}^{2} \mathrm{~s}\right)$ & $\mathrm{Ea}(\mathrm{KJ} / \mathrm{mol})$ & $\mathrm{n}\left(\mathrm{H}^{+}\right)$ \\
\hline Calcite & 10 & $5.01 \mathrm{E}-01$ & 14.4 & 1 & $1.55 \mathrm{E}-06$ & 23.5 & $3.31 \mathrm{E}-04$ & 35.4 & 1 \\
\hline Dolomite & 10 & $6.46 \mathrm{E}-04$ & 36.1 & 0.5 & $2.95 \mathrm{E}-08$ & 52.2 & $7.76 \mathrm{E}-06$ & 34.8 & 0.5 \\
\hline Illite & 100 & $1.05 \mathrm{E}-11$ & 23.6 & 0.34 & $1.66 \mathrm{E}-13$ & 35 & $3.02 \mathrm{E}-17$ & 58.9 & -0.4 \\
\hline K-feldspar & 10 & $8.71 \mathrm{E}-11$ & 51.7 & 0.5 & $3.89 \mathrm{E}-13$ & 38 & $6.31 \mathrm{E}-22$ & 94.1 & -0.82 \\
\hline Albite & 10 & $6.92 \mathrm{E}-11$ & 65 & 0.457 & $2.75 \mathrm{E}-13$ & 69.8 & $2.51 \mathrm{E}-16$ & 71 & -0.57 \\
\hline Kaolinite & 100 & $4.90 \mathrm{E}-12$ & 65.9 & 0.777 & $6.92 \mathrm{E}-14$ & 22.2 & $8.91 \mathrm{E}-18$ & 17.9 & -0.47 \\
\hline Anorthite & 10 & $3.16 \mathrm{E}-04$ & 16.6 & 1.411 & $7.59 \mathrm{E}-10$ & 17.8 & & & \\
\hline Muscovite & 100 & $1.00 \mathrm{E}-11$ & 23.6 & 0.34 & $1.66 \mathrm{E}-13$ & 35 & $3.02 \mathrm{E}-17$ & 58.9 & -0.4 \\
\hline Siderite & 10 & $6.46 \mathrm{E}-04$ & 36.1 & 0.5 & $1.26 \mathrm{E}-09$ & 62.76 & & 34.8 & 0.5 \\
\hline Ankerite & 10 & $6.46 \mathrm{E}-04$ & 36.1 & 0.5 & $1.26 \mathrm{E}-09$ & 62.76 & & & \\
\hline Quartz & 10 & & & & $1.00 \mathrm{E}-14$ & 87.7 & & & \\
\hline Pyrite $^{e}$ & 10 & & & & $1.94 \mathrm{E}-12$ & 53 & & & \\
\hline Pyrrhotite & \multicolumn{9}{|c|}{ Set to pyrite/ set to equilibrium } \\
\hline K-Montmorillonite & 100 & $2 \mathrm{E}-13$ & 48 & 0.22 & $3.89 \mathrm{E}-15$ & 48 & $3.89 \mathrm{E}-15$ & 48 & -0.13 \\
\hline Chlorite & 10 & $7.76 \mathrm{E}-12$ & 88 & 0.5 & $3.02 \mathrm{E}-13$ & 88 & & & \\
\hline Laumontite $^{\mathrm{f}}$ & 10 & $5 \mathrm{E}-13$ & & 0 & & & & & \\
\hline Daphnite & \multicolumn{9}{|c|}{ Set to kaolinite } \\
\hline Clinochlore & \multicolumn{9}{|c|}{ Set to kaolinite } \\
\hline Microcline & \multicolumn{9}{|c|}{ Set to K-feldspar } \\
\hline
\end{tabular}

All rate constants are listed for dissolution

${ }^{a}$ Reactive surface area

${ }^{\mathrm{b}}$ Rate constant

${ }^{\mathrm{c}}$ Activation energy

${ }^{\mathrm{d}} \mathrm{pH}$ dependency power term

${ }^{\mathrm{e}}$ Rate constant is obtained from the Arrhenius plot of the inverse of reaction temperature $\left(\right.$ at $25^{\circ} \mathrm{C}$ ) versus rate constant under 8 bars of hydrogen partial pressure (Truche et al. 2010)

${ }^{\mathrm{f}}$ Arthur et al. (2000)

applicability in hydrogen storage questionable. The rate constant of pyrite reduction by hydrogen is obtained from the experimental work of Truche et al. (2010). This particular study offers the most relevant and practical values for pyrite dissolution and pyrrhotite precipitation in the presence of hydrogen. The experimental kinetic rate constant for pyrite reduction to pyrrhotite by $\mathrm{H}_{2}$ was reported in the unit of $\left(\mathrm{mol} / \mathrm{m}^{2} / \mathrm{h}^{0.5)}\right.$. This unit needed to be converted to $\left(\mathrm{mol} / \mathrm{m}^{2} / \mathrm{s}\right)$. Truche, 2009 reproduced the dependency of the square root of time virtually by increasing the simulated reaction times. In our study, we reproduced this dependency by testing models with pyrite kinetic rate coefficient up to two orders of magnitude higher than the base model. Likewise, we made two case studies for pyrrhotite; in one the rate constant is set to be the same as pyrite and in the other one pyrrhotite reactions are assumed to be at equilibrium. No significant difference was observed in these case studies. In the last part, for pyrite and pyrrhotite, which are the minerals that may most likely react with hydrogen, an extra case study is considered and discussed in the simulation results section.

\section{Simulation results and discussion}

Batch geochemical modelling addresses the complex, thermodynamically controlled reactions between water, injected hydrogen gas and rock-forming minerals. The requirements for running simulations are the initial formation water chemistry, minerals mass (specified in grams) in equilibrium with the formation water and the kinetic parameters for the primary and secondary phases. In this chapter, the results from the equilibrium and kinetic batch models are shown and discussed. 


\section{Equilibrium batch models}

The prediction of the geochemical reactivity of hydrogen via equilibrium batch modelling is crucial to assess the potential long-term impacts on UHS on one hand, and on the other it allows to test different hypotheses concerning uncertain parametrization with simpler calculations. In these calculations, equilibrium of the aqueous phase with the injected $\mathrm{H}_{2}$ is maintained; likewise, mineral reactions with the formation water are considered at equilibrium. Two starting pointsi.e., initial conditions-were considered corresponding to case studies 3 and 4 from Table 4 . The initial state is equilibrated with injected hydrogen with a partial pressure up to 7.5 bars, corresponding to the operational $\mathrm{H}_{2}$ partial pressure during the injection operation. The reactions are monitored as a function of hydrogen fugacity. The formation of $\mathrm{CH}_{4}$ (aq) has been suppressed as its formation is not realistic and would lead to misinterpretations. As a further assumption, all other redox couple reactions are treated at equilibrium. As a consequence of hydrogen injection, primary minerals dissolve partially into the formation water, modifying the formation water composition, which leads to the precipitation of other mineral phases. Here, we present outcomes of a model, in which the calcite formation is excluded as it gave

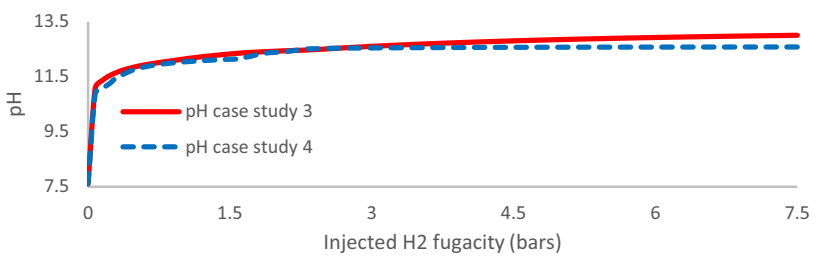

Fig. 3 Evolution of $\mathrm{pH}$ obtained from equilibrium batch models as a function of injected hydrogen fugacity more sensible results. The behavior of $\mathrm{pH}$ shows first a sharp peak, followed by a smooth increase, as shown in Fig. 3. In case study 3 , a slightly higher increase in $\mathrm{pH}$ value has been observed. The mineral reactions in the system explain this observation.

A detailed view on the mineral phase, mineral dissolutions and mineral precipitations alongside the variation in $\mathrm{pH}$ is provided in Fig. 4. The mineral reactions included in each case study are enumerated in Table 6.

The injection of hydrogen, and consequently the change in $\mathrm{pH}$ value, results in the formation of pyrrhotite from pyrite in reservoir conditions (Fig. 5). This reaction is understood to occur in the presence of hydrogen (Truche et al. 2013a, b, b; Betelu et al. 2012). The relationship between pyrite and pyrrhotite can be expressed by the general redox equation (Hall 1986): $2 \mathrm{FeS} \leftrightarrow \mathrm{FeS}_{2}+\mathrm{Fe}^{2+}+2 \mathrm{e}^{-}$.

Changes in aqueous species are expected and could be correlated with mineral dissolution and precipitation reactions. Figure 6 shows the changes in hydrogen sulfide, calcium, potassium, acetate and bicarbonate components as a function of the injected $\mathrm{H}_{2}$ fugacity. There is a noticeable decrease in a few aqueous species $\left(\mathrm{HCO}_{3}{ }^{-}\right.$,) with increasing $\mathrm{H}_{2}$ fugacity because of mineral precipitation. The dissolution of muscovite can explain the increase in $\mathrm{K}^{+}$in the system. The increase in sulfide and calcium concentrations are in agreement with the observed experimental trend in both species in the presence of hydrogen (Truche et al. 2010). The more pronouced production of $\mathrm{H}_{2} \mathrm{~S}$ at the beginning of the reaction was similarly in agreement with the experimental results (Truche et al. 2010).

The findings from the equilibrium batch models indicate that potential redox couples can play a big role in the consumption of hydrogen and increases in $\mathrm{pH}$. However, the likelihood of their occurrence within hydrogen storage
Fig. 4 Distribution of mineral phases (precipitation and dissolution, plotted on the primary $y$-axes) and $\mathrm{pH}$ variance (plotted on the secondary $y$-axes) obtained from equilibrium batch models as a function of injected hydrogen fugacity. Most changes occur at the beginning of injection; therefore, these plots are only shown for injection of $\mathrm{H}_{2}$ up to 3 bar fugacity (dissolution of primary minerals and precipitation of secondary minerals for case study 3 and 4 are shown in $\mathbf{a}-\mathbf{d}$, respectively)
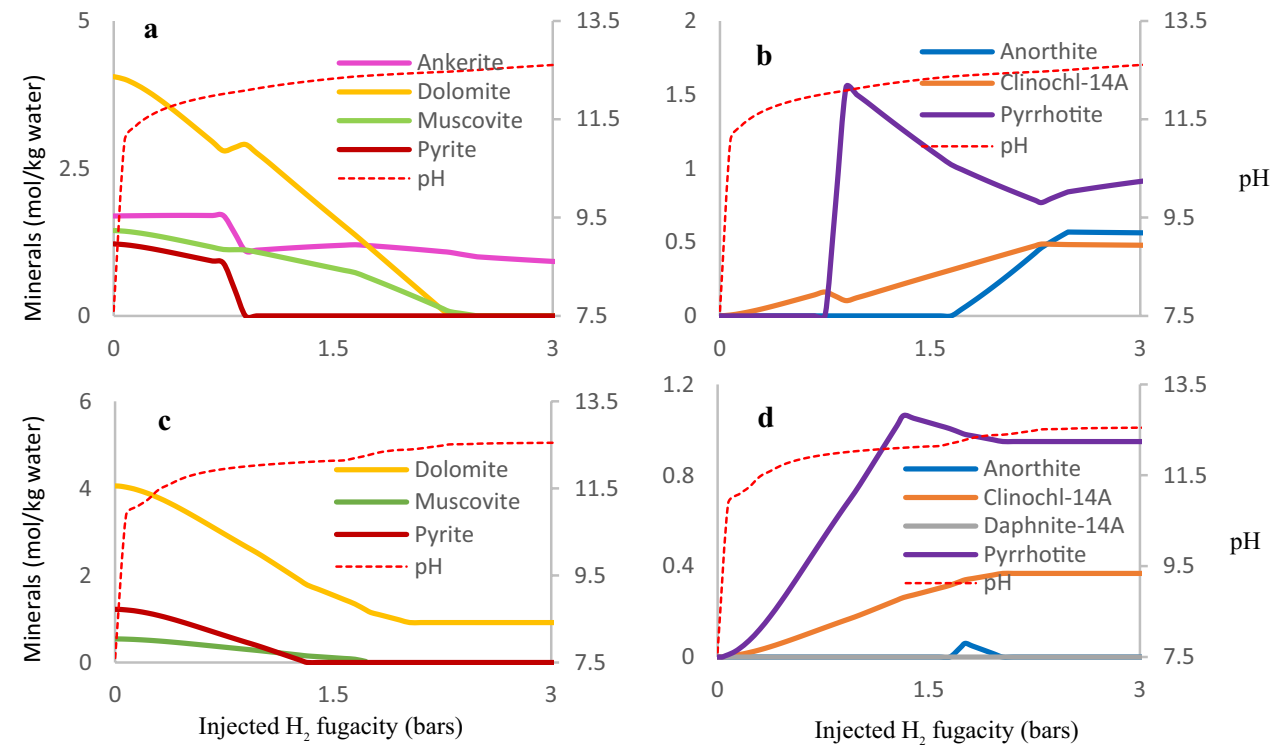
Table 6 Main chemical reactions extracted from equilibrium batch models marked by “*”

\begin{tabular}{|c|c|c|c|c|c|}
\hline \multirow[t]{2}{*}{ Mineral reaction } & \multirow[t]{2}{*}{ Precipitation/dissolution } & \multicolumn{4}{|c|}{ Case study } \\
\hline & & 3 & & 4 & \\
\hline Muscovite & Muscovite $+5 \mathrm{H}^{+}+5 \mathrm{H}^{+} \leftrightarrow \mathrm{K}^{+}+3 \mathrm{Al}^{+3}+3 \mathrm{SiO}_{2}(\mathrm{aq})+6 \mathrm{H}_{2} \mathrm{O}$ & $*$ & $\mathrm{P}$ & $*$ & $\mathrm{P}$ \\
\hline Dolomite & Dolomite $\leftrightarrow \mathrm{Ca}^{+2}+\mathrm{Mg}^{+2}+2 \mathrm{CO}_{3}^{2-}$ & $*$ & $\mathrm{P}$ & $*$ & $\mathrm{P}$ \\
\hline Pyrite & Pyrite $+\mathrm{H}_{2}(\mathrm{aq}) \leftrightarrow \mathrm{Fe}^{+2}+2 \mathrm{HS}^{-}$ & $*$ & $\mathrm{P}$ & $*$ & $\mathrm{P}$ \\
\hline Ankerite & Ankerite $+2 \mathrm{H}^{+} \leftrightarrow \mathrm{Fe}^{+2}+\mathrm{Ca}^{+2}+2 \mathrm{HCO}_{3}^{-}$ & $*$ & $\mathrm{P}$ & & \\
\hline Clinochlore & Clinochlore $+10 \mathrm{H}^{+} \leftrightarrow 2 \mathrm{AlO}(\mathrm{OH})+5 \mathrm{Mg}^{2+}+3 \mathrm{SiO}_{2}(\mathrm{aq})+8 \mathrm{H}_{2} \mathrm{O}$ & $*$ & $\mathrm{~S}$ & $*$ & $\mathrm{~S}$ \\
\hline Pyrrhotite & $\mathrm{FeS}_{2}+(1-\mathrm{x}) \mathrm{H}_{2} \leftrightarrow \mathrm{FeS}_{1+\mathrm{x}}+(1-\mathrm{x}) \mathrm{H}_{2} \mathrm{~S}$ & $*$ & $\mathrm{~S}$ & * & $\mathrm{S}$ \\
\hline Daphnite & Daphnite $+10 \mathrm{H}^{+} \leftrightarrow 2 \mathrm{AlO}(\mathrm{OH})+\mathrm{Fe}^{2+}+3 \mathrm{SiO}_{2}(\mathrm{aq})+8 \mathrm{H}_{2} \mathrm{O}$ & & & $*$ & $\mathrm{~S}$ \\
\hline
\end{tabular}

Primary and secondary minerals are indicated by "P" and "S"
Fig. 5 Dissolution of pyrite and formation of pyrrhotite as a consequence of hydrogen injection obtained from equilibrium batch model based on initial state of case study 3 and 4
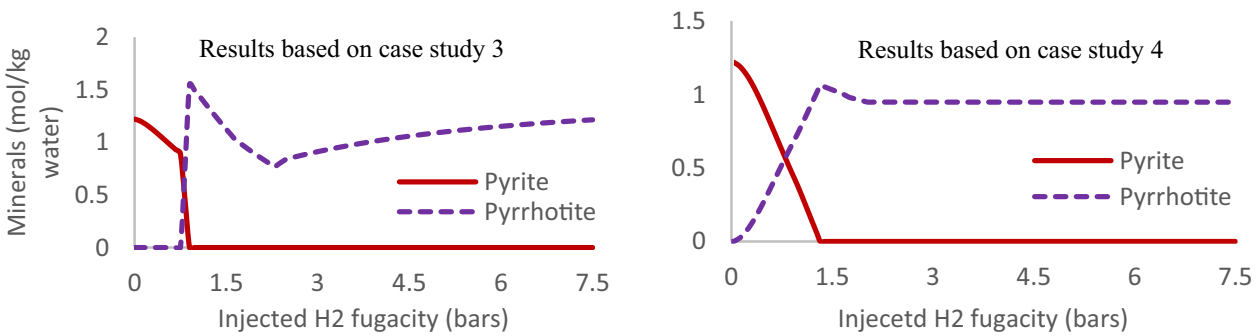
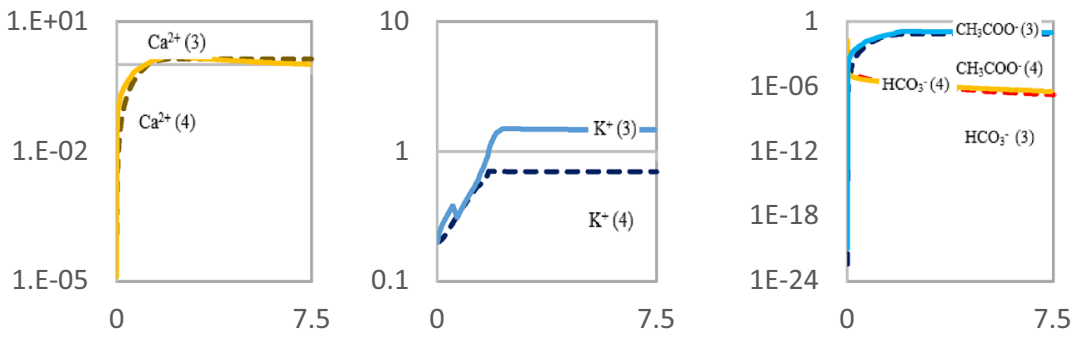

Injected $\mathrm{H}_{2}$ fugacity (bars)

Fig. 6 Major changes in aqueous chemical composition as function of injected gas fugacity results based on initial system from case study 3 and 4 are depicted as solid lines (3) and dashed lines (4), respectively

time cycles needs further investigation. Defining the rates of redox reactions in the presence of hydrogen requires laboratory data which are not yet widely existing within the various range of temperatures and hydrogen partial pressures. However, there are valuable experimental data for higher ranges of temperatures in presence of hydrogen, e.g., aqueous sulfate reduction by $\mathrm{H}_{2}$ at $250-300{ }^{\circ} \mathrm{C}$ under $4-16$ bars $\mathrm{H}_{2}$ partial pressure (Truche et al. 2009), nitrate reduction in the presence of $\mathrm{H}_{2}$ and specific catalyst (stainless steel $316 \mathrm{~L}$ and Hastelloy $\mathrm{C} 276$ ) at $90-150{ }^{\circ} \mathrm{C}$ under $0-10$ bars $\mathrm{H}_{2}$ partial pressure (Truche et al. 2013a, b, b), pyrite reduction into pyrrhotite at temperatures higher than $90{ }^{\circ} \mathrm{C}$ and under pressures higher than 10 bars $\mathrm{H}_{2}$ partial pressure pressures (Truche et al. 2010), and carbonates reduction (Berndt et al. 1996; McCollom and Seewald 2001). Many redox couples are unlikely to reach equilibrium (Sigg
2000). Nordstrom (2002) states that redox disequilibrium is the rule and that many redox species in water will not attain an equilibrium state freely. The main redox couples contributing to the consumption of hydrogen are identified as $\mathrm{CH}_{4}-\mathrm{HCO}_{3}{ }^{-}, \mathrm{HS}^{-}-\mathrm{SO}_{4}{ }^{2-}$, and $\mathrm{CH}_{4}-\mathrm{CH}_{3} \mathrm{COO}^{-}$. The $\mathrm{CH}_{4}-\mathrm{CH}_{3} \mathrm{COO}^{-}$redox couple seems irrelevant in the model as a very high formation of acetate is unreasonable (Seewald et al. 2006; Truche et al. 2010). In the presented equilibrium model, this redox pair was decoupled. There are some data available indicating that $\mathrm{H}_{2}$-induced redox reactions (pyrite reduction and the precipitation of pyrrhotite) can be substantial at low temperatures (Hall 1986; Betelu et al. 2012; Truche et al. 2013a, b). As the kinetic rates for the reactions of acetate/bicarbonate and methane/bicarbonate redox pairs are not reported in the literature, in the kinetic batch models, these redox pairs are decoupled. Assuming an equilibrium 
for the $\mathrm{HS}^{-} / \mathrm{SO}_{4}{ }^{2-}$ redox pair may be more relevant for the reaction of pyrite-pyrrhotite; however, previous studies show at the low temperature of the studied system this reaction must be decoupled as well (Kiyosu and Krouse 1993; Cross et al. 2004; Truche et al. 2009). As decoupling of the $\mathrm{HS}^{-} / \mathrm{SO}_{4}{ }^{2-}$ redox pair requires additional constraints, we have made disequilibrium assumption by adjusting the kinetic redox reaction with a negligible rate constant to this redox pair reaction to allow the pyrite-pyrrhotite reaction. The decoupling reaction among these redox pairs lessens the disturbance of the $\mathrm{pH}$ state; likewise, a higher amount of $\mathrm{H}_{2}$ stayed in the gas phase.

\section{Primary kinetic batch model}

Quantification of the chemical interactions related to a storage cycle requires a kinetic approach. Compared to equilibrium models, accurate kinetic data are scarce and are difficult to acquire, especially for complex systems as in the present case. A hydrogen storage cycle is typically limited to seasons-less than 1 year. Many of the mineral reactions occurring in equilibrium batch models would not occur on those relatively short timescales. Therefore, to understand what is more likely to occur within a hydrogen storage cycle, the integration of mineral reaction rates (listed in Table 5) was essential. Kinetic modelling indicates how fast the system reacts to a perturbation of its geochemical equilibrium state. In this section, we only show the results of the kinetic models based on the initial system of case study 3 , which we consider to be the most relevant. In the batch kinetic simulation, a typical cycle of hydrogen injection (we assume 12 months) with hydrogen partial pressure of 7.5 bar was considered. In the primary kinetic batch model, the mineral kinetic reaction rates were integrated in the model, while hydrogen dissolution in brine was assumed to be instantaneous.

Variations in $\mathrm{pH}$ and changes of mineral quantities in contact with hydrogen are displayed in Fig. 7. A minor $\mathrm{pH}$ increase is observed; likewise, changes in mineral quantities, which proceed extremely slowly, are only notable for primary minerals; none of the secondary minerals were formed in this case. As it was discussed earlier, two models were tested for pyrrhotite reaction rate; in one the rate constant is set to be the same as pyrite reaction rate and in the other reactions of pyrrhotite assumed to be at equilibrium. The results did not show any significant difference.

In the next model calcite was excluded from the secondary minerals and a kinetic rate was assigned to the redox pair of $\mathrm{HS}^{-} / \mathrm{SO}_{4}{ }^{2-}$. For this model, we implemented a zero ${ }^{\text {th }}$ order equation with rate constants ranging from $5 \mathrm{E}-9 \mathrm{~mol} / \mathrm{s}$ (Berta et al. 2018) to 5E-20 mol/s (considering slower rate constant for abiotic reactions). Only for rate constants lower than $1 \mathrm{E}-12$ did our kinetic simulations converge and produce meaningful results. The kinetic rate of $1 \mathrm{E}-12$ leads

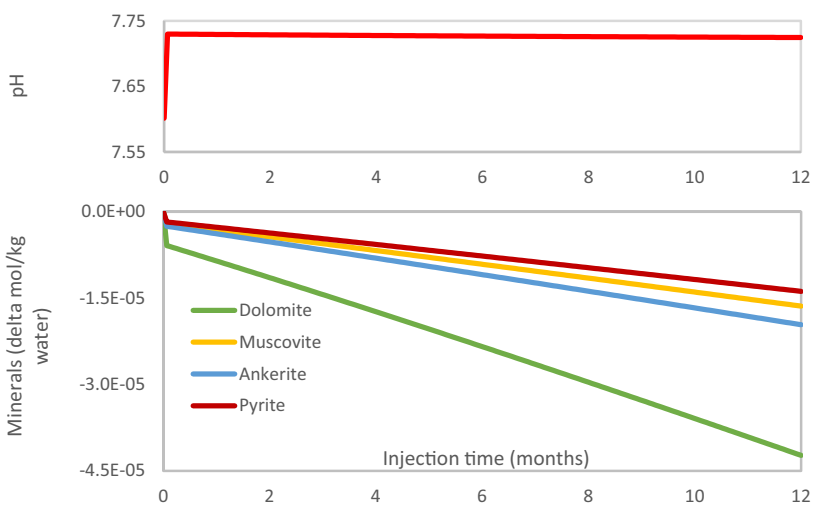

Fig. 7 Variation in $\mathrm{pH}$ (top panel) and mineral abundance change (bottom panel) within 1 year of injection at an $\mathrm{H}_{2}$ partial pressure of 7.5 bar (primary batch kinetic model based on initial system in case study 3 )

to the same results as what is already depicted in Fig. 7. Moreover, for the rate constant of $1 \mathrm{E}-20$ and decoupling, no $\mathrm{pH}$ increase was observed, still the minerals' change shows the same change illustrated in Fig. 7. As it has been discussed in the previous chapter, the major uncertainties in the kinetic model results are the assigned reaction rates, which are taken from laboratory experiments. These experiments are generally performed in the absence of a hydrogen partial pressure. Truche et al. (2013a, b) state that abiotic hydrogen redox reactivity is kinetically restricted and that many of the potentially hydrogen-induced redox reactions (e.g., sulfate and carbonate reduction) stay insignificant at low temperatures. However, there could be exceptions: a reduction of pyrite into pyrrhotite is one such possible exception. $\mathrm{pH}$ controls the extent of the reaction through alkaline conditions, which may promote pyrrhotite precipitation at lower temperatures and low hydrogen partial pressures. For these reasons, we ran another case study in which reactions of pyrite and pyrrhotite were considered at equilibrium. In this model, primary minerals and pyrrhotite alter the most during 1 year of hydrogen injection (Fig. 8).

Mineral reactions proceed faster than in the previous case, and although the changes are still minor, the $\mathrm{pH}$ increase is high and can be problematic (Fig. 9).

Despite the uncertainty in the equilibrium assumption for reactions of pyrite and pyrrhotite, this case study represents more realistic and reliable outcomes as these reactions are likely to occur in the presence of hydrogen. However, experimental data on reaction kinetics in the presence of hydrogen would be desirable and would reduce the uncertainties.

\section{Final kinetic batch model}

The equilibrium assumption for hydrogen reactions in brine in the primary kinetic batch model results in a large $\mathrm{pH}$ 
Fig. 8 Mineral abundance change within 1 year of injection at an $\mathrm{H}_{2}$ partial pressure of 7.5 bar (primary batch kinetic model based on initial system of case study 3 and assuming reactions of pyrite and pyrrhotite are at equilibrium)
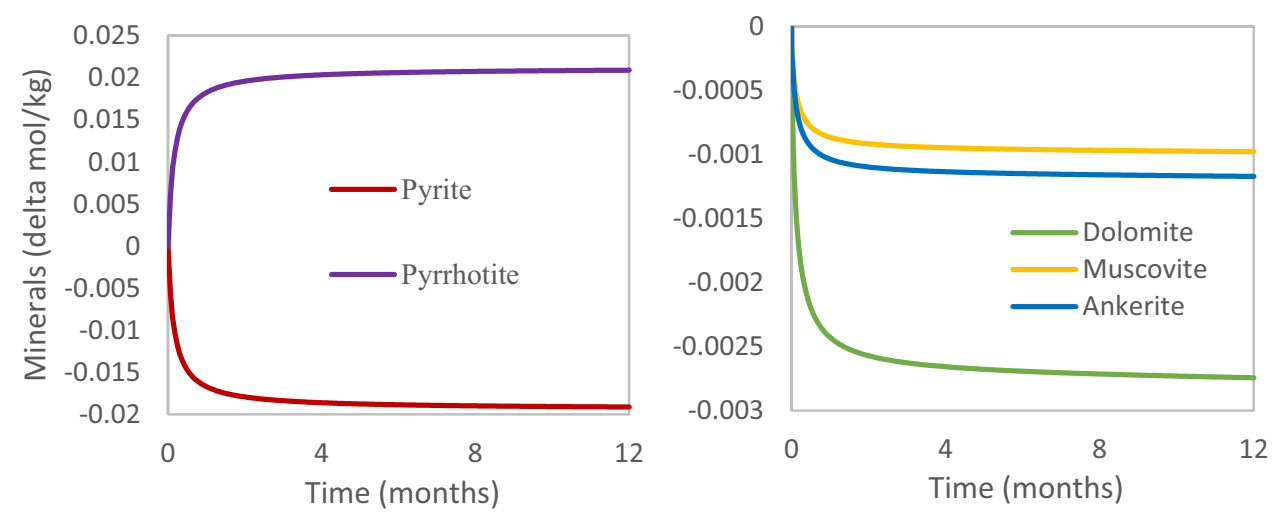

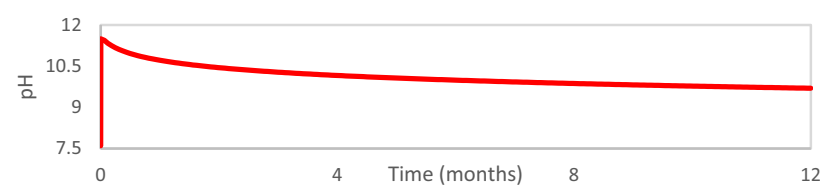

Fig. 9 Variation in $\mathrm{pH}$ (primary batch kinetic model based on initial system of case study 3 and assuming reactions of pyrite and pyrrhotite are at equilibrium)

increase that seems implausible in short timescales. In the final model, we consider the most realistic scenario, and we used the implemented gas transfer option to account for the hydrogen kinetic reaction rate. The equilibrium assumption for pyrite and pyrrhotite reactions is valid in this model. Literature data on hydrogen gas dissolution kinetics are not available, and we, therefore, defined three categories for kinetic parameters to account for slow, moderate, and fast reactions. Here, the presented terminologies as slow, moderate and high rates (shown in Table 7) serve as rough estimates for the speed of reactions in the presence of hydrogen in a typical storage cycle (12 months) with the operational hydrogen partial pressure of 7.5 bars. These values are determined based on numerous simulations performed to determine the impact of kinetic rate on the $\mathrm{pH}$ rise for this particular model. It should be noted that these values are approximations based on simulations in our specific case study and may not be generalised. Varying the kinetic ratecontrolling parameters classifies scenarios that can possibly occur in our reservoir. The gas transfer is a rate-expression option that describes the dissolution of gases from an external reservoir. The rate $r_{k}^{\rightarrow}(\mathrm{mol} / \mathrm{s})$ at which a kinetic gas dissolves into the fluid is calculated via the built-in equation:

$r_{k}^{\overrightarrow{1}}=n_{\mathrm{w}} A_{\mathrm{sp}} k_{+}\left(f_{\mathrm{ext}}-f_{k^{\rightarrow}}\right)$,

$n_{\mathrm{w}}$ accounts for the solvent mass $(\mathrm{kg}), k_{+}$is the rate constant $\left(\mathrm{mol} / \mathrm{cm}^{2} \mathrm{sec}\right), A_{\mathrm{sp}}$ is the specific contact area $\left(\mathrm{cm}^{2} / \mathrm{kg}\right.$ water) between the reservoir and fluid, and $f_{\text {ext }}$ and $f_{k \rightarrow}$ are the external and in-fluid gas fugacity. For convenience, we defined a new variable $\alpha(\mathrm{mol} / \mathrm{kg}$ water sec $)$, which is the product of $A_{\mathrm{sp}}$ and $k_{+}$.

The results of the selected case study $(\alpha[\mathrm{mol} /(\mathrm{kg}$ (water) s)]: $1 \mathrm{E}-7$; injected $\mathrm{H}_{2}$ fugacity: 7.5 bar; time span: 1 year) are shown below. This case study accounts for quite a high reaction rate of hydrogen. Compared to the primary kinetic model, assigning a kinetic rate for hydrogen solubility controls the increase of $\mathrm{pH}$ in the system (Fig. 10).

Minerals abundance change is negligible and at a lower amount compared to the previous case (Fig. 11).

The effect of the $\mathrm{H}_{2}$ dissolution rate on the $\mathrm{pH}$ increase is tested within 1 year of hydrogen injection. Furthermore, the influence of redox pair equilibrium is investigated for the different models (Table 7).

In the case of assuming disequilibrium for redox pairs, when the hydrogen reaction rate remains relatively low, the $\mathrm{pH}$ increase is minor, and hydrogen gas acts like an inert gas in the system. This is valid for the case where the equilibrium assumption is considered for redox pairs. In the cases
Table 7 Sensitivity analysis of kinetic rate-controlling parameters for hydrogen reactions; three rate constants (high, moderate, and slow) are tested with variations of specific contact area and external $\mathrm{H}_{2}$ fugacity (after 12 months with fugacity of 7.5 bars)

\begin{tabular}{llll}
\hline Case & $\begin{array}{l}\alpha(\mathrm{mol} /(\mathrm{kg} \text { water } \\
\mathrm{s}))\end{array}$ & $\mathrm{pH}$ increase & \\
\cline { 3 - 4 } & & $\begin{array}{l}\text { Disabling redox pairs and } \\
\text { formation of } \mathrm{CH} 4\end{array}$ & $\begin{array}{l}\text { Assuming equi- } \\
\text { librium for redox } \\
\text { couples }\end{array}$ \\
\hline High $\mathrm{H}_{2}$ kinetic rate & $1 \mathrm{E}-07$ & 0.1148 & 3.67 \\
Moderate $\mathrm{H}_{2}$ kinetic rate & $1 \mathrm{E}-10$ & 0.1148 & 2.88 \\
Low $\mathrm{H}_{2}$ kinetic rate & $1 \mathrm{E}-13$ & 0.0191 & 0.0039 \\
\hline
\end{tabular}




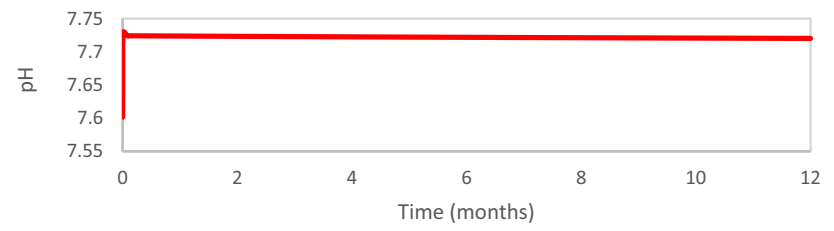

Fig. 10 The evolution of $\mathrm{pH}$ as a consequence of hydrogen injection within 1 year (obtained from the final kinetic model; $A_{\mathrm{sp}}$ specific contact area $\left(\mathrm{cm}^{2} / \mathrm{kg}\right.$ water $): 1$; rate constant $\left(\mathrm{mol} /\left(\mathrm{cm}^{2} \mathrm{~s}\right)\right): 1 \mathrm{e}-7$; injected $\mathrm{H}_{2}$ fugacity: 7.5 bar)

of the moderate and high hydrogen rate constants, a higher increase in $\mathrm{pH}$ is observed; however, this amount remains insignificant. It is worth noting that the changes in mineral abundances in all cases are negligible. The equilibrium assumption for redox pairs in these cases triggers hydrogen consumption and results in the considerable $\mathrm{pH}$ increase.

\section{Summary and conclusions}

In this paper, a geochemical modelling workflow is presented to study and quantify potential geochemical processes that can lead to hydrogen loss in a hydrogen storage site in the Molasse Basin, Upper Austria. The processes were investigated by equilibrium and kinetic batch models at constant pressure and temperature. The modelling methodology considers site-specific mineralogy, mineral reaction rates obtained from the literature and coupling to fast equilibrium processes, such as aqueous speciation reactions. To investigate the short- and long-term impacts of hydrogen on the reservoir, various batch geochemical scenarios were modelled.

In the first stage, all possible reactions within phases were identified by imposing an equilibrium assumption for hydrogen-brine-mineral reactions. The model outcomes indicate that hydrogen can considerably influence the integrity of the reservoir. Giving enough time for all reactions to occur (e.g., carbonate dissolution/precipitation, redox reactions and aqueous speciation) results in a substantial $\mathrm{pH}$ increase. The $\mathrm{CH}_{4}-\mathrm{HCO}_{3}{ }^{-}, \mathrm{HS}^{-}-\mathrm{SO}_{4}{ }^{2-}$, and $\mathrm{CH}_{4}-\mathrm{CH}_{3} \mathrm{COO}^{-}$redox couples are the main sinks for hydrogen consumption in the system. Furthermore, the presence of $\mathrm{H}_{2}$ in this system affects the thermodynamic stability of pyrite and the redox reaction in which pyrite is reduced to pyrrhotite.

In the following stage, the kinetic rates parameters for the primary and secondary minerals were included in the primary kinetic model. The $\mathrm{CH}_{4}-\mathrm{HCO}_{3}{ }^{-}$and $\mathrm{CH}_{4}-\mathrm{CH}_{3} \mathrm{COO}^{-}$redox couples are decoupled to approach realistic conditions. The results indicate that geochemical reactions of $\mathrm{H}_{2}$ with minerals are generally slow kinetic rates obtained from literature. Apart from few studies (Betelu et al. 2012; Truche et al. 2010), the kinetic parameters are generally derived in absence of a hydrogen gas phase or at very high temperatures which it is not applicable to this study; thus, uncertainty with regards to these rates is considered. A case study in which reactions of pyrite-pyrrhotite are considered at equilibrium estimated which of the revealed hydrogen reactions with these minerals is fast enough to effectively increase $\mathrm{pH}$ in the system. The latter model is most relevant to the application of underground hydrogen storage.

Finally, hydrogen dissolution kinetics were added to the model. The dissolution kinetic rate is based on a typical storage cycle (12 months) and operational hydrogen partial pressure of 7.5 bars which is derived from many simulations for this specific case study. Owing to a lack of data for kinetic hydrogen dissolution reactions in the literature, we defined several scenarios to understand under which conditions the likelihood of hydrogen loss is considerable. We further compared the same models to cases in which the reactions of redox couples remained at equilibrium. When applying assumptions of both disequilibrium and equilibrium for reactions of redox couples, when the hydrogen reaction rate remains low, the $\mathrm{pH}$ increase is minor, and hydrogen behaves like an inert gas. In the case of moderate-to-high hydrogen
Fig. 11 Mineral abundance changes (obtained from final kinetic model; $A_{\mathrm{sp}}$ specific contact area $\left(\mathrm{cm}^{2} / \mathrm{kg}\right.$ water $): 1$; rate constant $\left(\mathrm{mol} /\left(\mathrm{cm}^{2} \mathrm{~s}\right)\right): 1 \mathrm{e}-7$; injected $\mathrm{H}_{2}$ fugacity: 7.5 bar)

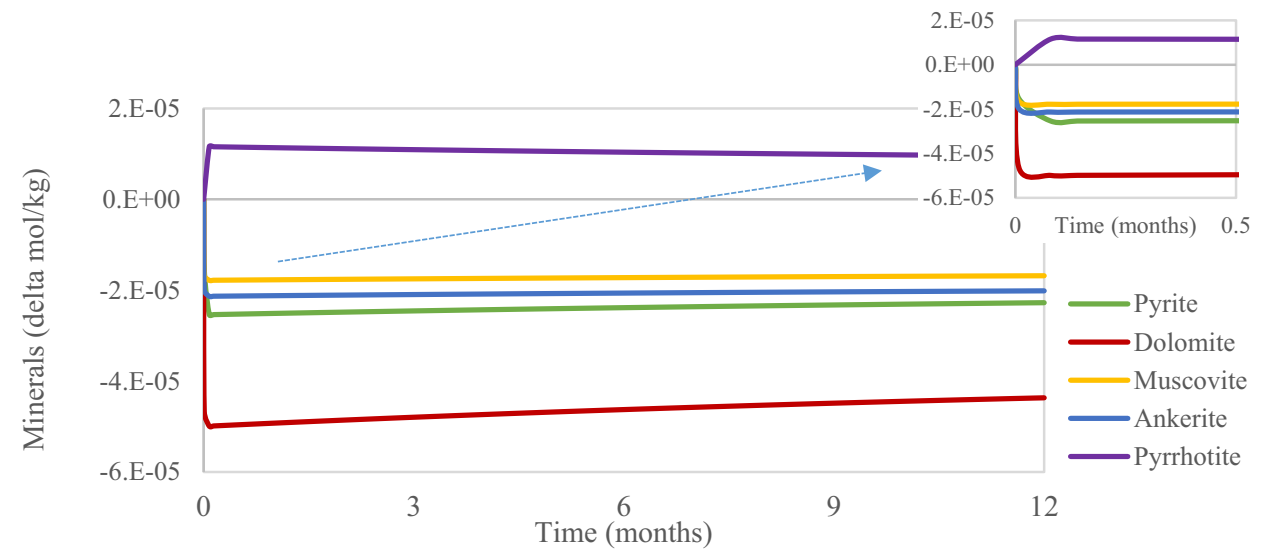


rate constants, a higher increase in $\mathrm{pH}$ is observed; however, this amount remains insignificant when assuming disequilibrium for redox couple reactions and is substantial in the case of the equilibrium assumption for these reactions.

From the modelling results, we conclude that the main reason for an increase in $\mathrm{pH}$ and consequently hydrogen loss is the equilibrium assumption among redox pairs and the pyrite reduction to pyrrhotite. The question of whether local equilibrium for redox pairs is a reasonable assumption must be addressed using the appropriate data, which requires further experimental investigation. The abiotic hydrogen redox reactivity is kinetically restricted, and many of the potential hydrogen-induced redox reactions tend to stay negligible at low temperatures. The exception for $\mathrm{H}_{2}$-induced redox reactions is pyrite reduction into pyrrhotite, which can be significant at low-temperature conditions. Alkaline $\mathrm{pH}$ conditions may further promote pyrrhotite precipitation. Quantifying how much hydrogen will be lost due to geochemical reactions is out of the scope of this work.

Considering the full range of uncertainty mainly caused by the lack of reliable kinetic data, the risk of hydrogen loss and the disturbance of reservoir integrity associated with geochemical interactions with hydrogen cannot generally be ruled out. The potential risk of hydrogen loss increases when redox couple reactions are assumed to be at equilibrium. The reaction rates incorporated in this work that were obtained from literature data are mainly derived from laboratory experiments. It is important to note that fieldscale reaction rates are often orders of magnitude lower than laboratory values (Dentz et al. 2011; Steefel et al. 2005; White and Brantley 2003). Consequently, we expect more moderate results in terms of disturbance in field applications than those observed in the simulations-this study is a conservative risk assessment. It should also be noted that the present simulation results are site-specific; therefore, particular consideration should be paid when extrapolating the outcomes and conclusions to other storage sites.

\begin{abstract}
Acknowledgements Open access funding provided by Montanuniversität Leoben. We would like to express our gratitude to the sponsoring agencies, the Austrian Research Promotion Agency (FFG) and "Klimaund Energiefonds". We would like to thank RAG (Rohöl-Aufsuchungs Aktiengesellschaft) for providing the field data used in this study. Furthermore, we would like to thank the GWB support team for their helpful comments and feedback to our questions. We would like to thank the two reviewers, Dr Laurent Truche and the second anonymous reviewer for their insightful comments that remarkably improved the manuscript.
\end{abstract}

Open Access This article is distributed under the terms of the Creative Commons Attribution 4.0 International License (http://creativeco mmons.org/licenses/by/4.0/), which permits unrestricted use, distribution, and reproduction in any medium, provided you give appropriate credit to the original author(s) and the source, provide a link to the Creative Commons license, and indicate if changes were made.

\section{References}

Aqueous Solutions LLC (2016) https://www.gwb.com/

Arthur R, Savage D, Sasamoto H, Shibata M, Yui M (2000) Compilation of kinetic data for geochemical calculations. Japan Nuclear Cycle Development Institute, Tokaimura

Berndt ME, Allen DE, Seyfried JW (1996) Reduction of $\mathrm{CO}_{2}$ during serpentinization of olivine at $300{ }^{\circ} \mathrm{C}$ and 500 bar. Geology 24(4):351-354. https://doi.org/10.1130/00917613(1996)024\%3C0351:ROCDSO\%3E2.3.CO;2

Berta M, Dethlefsen F, Ebert M, Schäfer D, Dahmke A (2018) Geochemical effects of millimolar hydrogen concentrations in groundwater: an experimental study in the context of subsurface hydrogen storage. Environ Sci Technol 52:4937-4949. https:// doi.org/10.1021/acs.est.7b05467

Betelu S, Lerouge C, Berger G, Giffaut E, Ignatiadis I (2012) Mechanistic and kinetic study of pyrite $\left(\mathrm{FeS}_{2}\right)$-hydrogen $(\mathrm{H} 2)$ interaction at $25^{\circ} \mathrm{C}$ using electrochemical techniques. In: International meeting "clays in natural and engineered barriers for radioactive waste confinement", Montpellier, France. https://hal-brgm.archi ves-ouvertes.fr/hal-00703578. Accessed 27 Nov 2017

Bethke CM, Farrell B, Yeakel S (2018) GWB essentials guide. Aqueous Solutions LLC, Champaign, Illinois

Cantucci B, Montegrossi G, Vaselli O, Tassi F, Quattrocchi F, Perkins E (2009) Geochemical modeling of $\mathrm{CO}_{2}$ storage in deep reservoirs: the Weyburn Project (Canada) case study. Chem Geol 265:181-197. https://doi.org/10.1016/j.chemg eo.2008.12.029

Carden P, Paterson L (1979) Physical, chemical and energy aspects of underground hydrogen storage. Int J Hydrogen Energy 4(6):559_ 569. https://doi.org/10.1016/0360-3199(79)90083-1

Cross M, Manning D, Bottrell S, Worden R (2004) Thermochemical sulphate reduction (TSR): experimental determination of reaction kinetics and implications of the observed reaction rates for petroleum reservoirs. Org Geochem 35:393-404. https://doi. org/10.1016/j.orggeochem.2004.01.005

De Ruig M, Hubbard S (2006) Seismic facies and reservoir characteristics of a deep-marine channel belt in the Molasse foreland basin, Puchkirchen Formation, Austria. AAPG Bulletin 90(5):735-752. https://doi.org/10.1306/10210505018

De Lucia M, Bauer S, Beyer C, Kühn M, Nowak T, Pudlo D, Stadler $\mathrm{S}$ (2012) Modelling $\mathrm{CO}_{2}$-induced fluid-rock interactions in the Altensalzwedel gas reservoir. Part I: from experimental data to a reference geochemical model. Environ Earth Sci. https://doi. org/10.1007/s12665-012-1725-9

Dentz M, Gouze P, Carrera J (2011) Effective non-local reaction kinetics for transport in physically and chemically heterogeneous media. J Contam Hydrol. https://doi.org/10.1016/j.jconh yd.2010.06.002

Fanning J (2000) The chemical reduction of nitrate in aqueous solution. Coord Chem Rev 199(1):159-179. https://doi.org/10.1016/S0010 $-8545(99) 00143-5$

Foh S, Novil M, Rockar E, Randolph P (1979) Underground hydrogen storage final report. Institute of Gas Technology, Chicago

Freeze R, Cherry J (1979) Groundwater. Prentice-Hall, Englewood Cliffs

Gaus I, Audigane P, André L, Lions J, Jacquemet N, Durst P,.. . Azaroual $\mathrm{M}$ (2008) Geochemical and solute transport modelling for $\mathrm{CO}_{2}$ storage, what to expect from it? Int J Greenhouse Gas Control 2(4):605-625. https://doi.org/10.1016/j.ijggc.2008.02.011

Hall A (1986) Pyrite-pyrrhotine redox reactions in nature. Mineral Mag 50:223-229

Holland T, Powell R (1998) An internally consistent thermodynamic data set for phases of petrological interest. J Metamorph Geol 16(3):309-343 
Kiyosu Y, Krouse H (1993) Thermochemical reduction and sulfur isotopic behavior of sulfate by acetic acid in the presence of native sulfur. Geochem J 27(1):49-57. https://doi.org/10.2343/geoch emj.27.49

Klein E, De Lucia M, Kempka T, Kühn M (2013) Evaluation of longterm mineral trapping at the Ketzin pilot site for $\mathrm{CO}_{2}$ storage: an integrative approach using geochemical modelling and reservoir simulation. Int J Greenh Gas Control 19:720-730. https://doi. org/10.1016/j.ijggc.2013.05.014

McCollom T, Seewald J (2001) A reassessment of the potential for reduction of dissolved $\mathrm{CO}_{2}$ to hydrocarbons during serpentinization of olivine. Geochim Cosmochim Acta 65(21):3769-3778. https://doi.org/10.1016/s0016-7037(01)00655-x

Nordstrom D (2002) Aqueous redox chemistry and the behavior of iron in acid mine waters. In: Workshop on monitoring oxidationreduction processes for ground-water restoration, pp 43-47

Palandri J, Kharaka Y (2004) A compilation of rate parameters of water-mineral interaction kinetics for application to geochemical modeling. US Geological Survey, Washington

UNDERGROUND.SUN.STORAGE (2016). RAG Austria. http://www. underground-sun-storage.at/

Seewald J, Zolotov M, McCollom T (2006) Experimental investigation of single carbon compounds under hydrothermal conditions. Geochim Cosmochim Acta 70(2):446-460. https://doi.org/10.1016/j. gca.2005.09.002

Sigg L (2000) Redox potential measurements in natural waters: significance, concepts and problems. In: Schüring J, Schulz H, Fischer W, Böttcher J, Duijnisveld W (eds) Redox-fundamentals, processes and applications. Springer, Berlin, pp 1-12. https://doi. org/10.1007/978-3-662-04080-5_1

Steefel C, DePaolo D, Lichtner P (2005) Reactive transport modeling: an essential tool and a new research approach for the Earth sciences. Earth Planet Sci Lett 240:539-558. https://doi. org/10.1016/j.eps1.2005.09.017

Taylor J, Alderson J, Kalyanam K, Lyle A, Phillips L (1986) Techni$\mathrm{cal}$ and economic assessment of methods for the storage of large quantities of hydrogen. Int J Hydrogen Energy 11(1):5-22. https ://doi.org/10.1016/0360-3199(86)90104-7
Truche L (2009) Transformations minéralogiques et géochimiques induites par la présence d'hydrogène dans un site de stockage de déchets radioactifs. Université Paul Sabatier, Géochimie, Toulouse III. https://tel.archives-ouvertes.fr/tel-00439788. Accessed 27 Nov 2017

Truche L, Berger G, Destrigneville C, Pages A, Guillaume D, Giffaut E, Jacquot E (2009) Experimental reduction of aqueous sulfate by hydrogen under hydrothermal conditions: implication for the nuclear waste storage. Geochim Cosmochim Acta 73(16):48244835. https://doi.org/10.1016/j.gca.2009.05.043

Truche L, Berger G, Destrigneville C, Guillaume D, Giffaut E (2010) Kinetics of pyrite to pyrrhotite reduction by hydrogen in calcite buffered solutions between 90 and $180^{\circ} \mathrm{C}$ : implications for nuclear waste disposal. Geochim Cosmochim Acta 74(10):28942914. https://doi.org/10.1016/j.gca.2010.02.027

Truche L, Jodin-Caumon M-C, Lerouge C, Berger G, Mosser-Ruck R, Giffaut E, Michau N (2013a) Sulphide mineral reactions in clay-rich rock induced by high hydrogen pressure. Application to disturbed or natural settings up to $250{ }^{\circ} \mathrm{C}$ and 30 bar. Chem Geol 351:217-228. https://doi.org/10.1016/j.chemgeo.2013.05.025

Truche L, Berger G, Albrecht A, Domerg L (2013b) Engineered materials as potential geocatalysts in deep geological nuclear waste repositories: a case study of the stainless steel catalytic effect on nitrate reduction by hydrogen. Appl Geochem 35:279-288. https ://doi.org/10.1016/j.apgeochem.2013.05.001

White A, Brantley S (2003) The effect of time on the weathering of silicate minerals: why do weathering rates differ in the laboratory and field? Chem Geol 202(3-4):479-506. https://doi.org/10.1016/j. chemgeo.2003.03.001

Zhu C, Anderson G (2002) Environmental applications of geochemical modeling. Cambridge University Press, Cambridge. https://doi. org/10.1017/CBO9780511606274

Publisher's Note Springer Nature remains neutral with regard to jurisdictional claims in published maps and institutional affiliations. 